\title{
A video of best practice recommendations for making botulinum toxin therapy safe during the COVID-19 pandemic
}

\author{
Francesco Bono ${ }^{1}$ ( ) Maria Concetta Altavista ${ }^{2} \cdot$ Roberto Eleopra $^{3} \cdot$ on behalf of the Italian Botulinum Toxin Network \\ -study group of Italian Society of Neurology
}

Received: 24 April 2021 / Accepted: 31 May 2021 / Published online: 19 July 2021

(c) Fondazione Società Italiana di Neurologia 2021, corrected publication 2022

\begin{abstract}
The physician and patient come into close contact during botulinum toxin treatments, increasing the chances of COVID-19 infection. Therefore, it is essential to use an effective injection method that can prevent infection with SARS-CoV-2 virus. In order to minimize the risk of SARS-CoV-2 transmission during botulinum toxin treatment in the COVID-19 era, the Italian Botulinum Toxin Network study group of the Italian Society of Neurology has prepared a video of best practice recommendations on how to organize the work of a clinic performing botulinum toxin treatments.
\end{abstract}

Keywords Safe botulinum toxin injection $\cdot$ COVID-19 pandemic $\cdot$ SARS-CoV-2 infection · Italian Botulinum Toxin Network recommendations

The following text summarizes information provided in the video:

\section{Overview}

In order to minimize the risk of SARS-CoV-2 transmission during botulinum toxin treatment in the COVID-19 era, the Italian Botulinum Toxin Network has prepared a video of best practice recommendations to make botulinum toxin therapy safe in patients with dystonia, spasticity, chronic migraine, primary hyperhidrosis and sialorrhea [1].

\section{Recommendations to prevent SARS-CoV-2 infection during botulinum toxin treatment}

Structural recommendations [2]:

Francesco Bono

f.bono@unicz.it

1 Center for Botulinum Toxin Therapy, Neurology Unit, A.O.U. Mater Domini, 88100 Catanzaro, CZ, Italy

2 Neurology Unit, San Filippo Neri Hospital ASL Roma 1, Rome, Italy

3 Neurological Unit 1, Fondazione IRCSS, Istituto Neurologico "Carlo Besta", Milan, Italy
Daily sanitization of environments to be used for botulinum toxin infiltration;

Control of the patient's body temperature at the entrance to the facility;

Arrangement of suitable interpersonal distancing measures in the waiting room;

Availability and provision of personal protective equipment (PPE) such as surgical masks or FFP2, footwear, headgear, disposable gown, gloves and visors/glasses and sanitizing agents for healthcare personnel [3];

Disposable material, hand disinfectant and surgical masks for the patient.

Patients are instructed as follows:

Come to the outpatient clinic with a protective surgical mask and nitrile gloves (also for accompanying persons);

The accompanying person must wear the protective surgical mask and, after accompanying the patient, must wait outside the clinic or hospital during treatment with botulinum toxin.

Botulinum toxin injection procedure:

The patient must treat the hands with hydroalcoholic or chlorine gel before entering the clinic. It is mandatory for the patient to wear non-sterile gloves and a surgical mask;

Doctor and staff remove all jewellery and personal items. Wash hands for at least $20 \mathrm{~s}$ with soap and water or alcohol solution. Wear the first pair of gloves. Wear footwear and headgear, then over the uniform the disposable gown, then 
mask FFP2; wear goggles or visor and wear the second pair of gloves [4];

When changing each patient, follow the sequence indicated, remove the second pair of gloves together with the disposable gown, remove the goggles or visor and sanitize them. Practice hand hygiene with soap and water or alcohol solution. In addition, if the botulinum toxin infiltration procedure involves treatment in the craniocervical districts or near the oral cavity [5], it is mandatory that healthcare professionals change the FFP2 mask after each infiltration [6], unless a protective visor is used;

Clean all surfaces with which the patient has come into contact (bed, chair) when changing patients with hydroalcoholic disinfectants (ethyl alcohol at $70^{\circ}$ ) or chlorinated disinfectants $(0.1 \%$ sodium hypochlorite solutions). The most exposed surfaces should be protected with disposable barriers which, at the end of the session, should be replaced by special waste. Frequently change the air between patients in the clinic [7].

\section{Conclusions}

When these instructions are properly followed, they make the botulinum toxin injection procedure safe for the patient and the medical staff. New knowledge about SARS-CoV-2 infection may lead to changes in the suggested rules of good practice.

Supplementary Information The online version contains supplementary material available at https://doi.org/10.1007/s10072-021-05375-z.

Acknowledgements Italian Botulinum Toxin Network Safe Infiltration Project participants:

Albanese M.; Albani G.; Assetta M.; Autunno M.; Babbini M.T.; Balestrieri F.; Barbero P.; Barbieri S.; Bargellesi S.; Bentivoglio A.; Bertolasi L.; Bizza M.; Capone L.; Cassano D.; Castagna A.; Castronovo G.; Cerchi A.; Cesaretti C.; Cevoli S.; Coletti Moja M.; Corradini C.; Crapanzano F.; Danni M.C.; De Bartolo M.; De Fazio G.; Del Colle R.; Doretti A.; Fazio N.; Flamma G.; Frasson E.; Frontoni M.; Giorgianni R.; Girlanda P.; Grazzi L.; Inglese C.; Leggio U.; Lettieri C.; Liberini P.; Liotti V.; Lo Fermo S.; Lori S.; Lozza A.; Maggi L.; Maggioni G.; Mampreso E.; Manzo L.; Marchese R.; Marinelli L.; Masi G.; Milano E.; Misceo S.; Moccia M.; Osio M.; Petracca M.; Pascarella A.; Polidori L.; Pozzolante R.; Prudenzano M.P.; Romano M.C.; Rossi V.; Sacco S.; Sances G.; Santoro A.; Scaglione Cesa L.;
Sidoti V; Soliveri P.; Squintani G.M.; Tambasco N.; Terranova C.; Torelli P.; Truscello C.; Valzania F.

Data availability The data that support the findings of this study are available on request from the corresponding author.

Code availability Not applicable.

\section{Declarations}

Conflict of interest The authors declare no competing interests.

Ethical approval Institutional Review Board approval was obtained for this study.

Consent to participate Not applicable.

Consent for publication Not applicable.

\section{References}

1. Bono F et al Safety recommendations for treatment with botulinum toxin during the COVID-19 pandemic prepared by the Italian Botulinum Toxin Network in collaboration with the Accademia Limpe-Dismov, Sisc and Anircef Associations. Abstract Toxins Virtual Congress 2021.

2. World Health Organization (2020) Getting your workplace ready for COVID-19: How COVID-19 spreads.

3. Ortega $\mathrm{R}$ et al (2020) Personal protective equipment and COVID19. N Engl J Med 382(26):e105

4. Centers for Disease Control and Prevention Coronavirus disease 2019 (COVID-19): using personal protective equipment (PPE). https://www.cdc.gov/coronavirus/2019-ncov/hcp/using-ppe.html

5. van Doremalen N et al (2020) Aerosol and surface stability of SARS-CoV-2 as compared with SARS-CoV-1. N Engl J Med 382:1564-1567

6. Degesys NF et al (2020) Correlation between N95 extended use and reuse and fit failure in an emergency department. JAMA 324(1):94-96

7. Food and Drug Administration (2020) Enforcement policy for sterilizers, disinfectant devices, and air purifiers during the coronavirus disease 2019 (COVID-19) public health emergency

Publisher's note Springer Nature remains neutral with regard to jurisdictional claims in published maps and institutional affiliations.

Springer Nature or its licensor (e.g. a society or other partner) holds exclusive rights to this article under a publishing agreement with the author(s) or other rightsholder(s); author self-archiving of the accepted manuscript version of this article is solely governed by the terms of such publishing agreement and applicable law. 